\title{
Surgical Field Fire Involving a Premature Neonate
}

\author{
Laraib Rasul $^{1}$, Naeem Liaqat ${ }^{1}$, Raja Imran², Navira Javed ${ }^{1}$ and Shoaib Hasan ${ }^{2}$ \\ ${ }^{1}$ Department of Paediatric Surgery, Holy Family Hospital, Rawalpindi, Pakistan \\ ${ }^{2}$ Department of Paediatric Medicine, Holy Family Hospital, Rawalpindi, Pakistan
}

\begin{abstract}
Surgical field fire is a very rare intraoperative complication and has potentially serious consequences. Cases of surgical field fire have been reported in literature. Usually, surgical field fire involves airway, but it can also occur in surgical field. We, hereby report a case of surgical field fire while operating on a 4-week baby for jejunal atresia. In this case report, we review causes and preventive measures for surgical field fire.
\end{abstract}

Key Words: Surgical field, Fire, Neonate, Prevention, Operation theatre.

How to cite this article: Rasul L, Liaqat N, Imran R, Javed N, Hasan S. Surgical Field Fire Involving a Premature Neonate. J Coll Physicians Surg Pak 2020; 30(07):760-761.

\section{INTRODUCTION}

Surgical field fire occurs very rarely. Most commonly reported cases of surgical field fire occur during laryngeal, pharyngeal, tracheostomy, and bronchoscopy procedures. Usually, fire occurs in the airway (34\%), head and neck area (28\%), and only a small fraction occurs in the surgical field. Consequences of surgical field fire can be deadly. For prevention of fires, it is necessary to understand fire triangle and also methods for reducing the risk of fire. ${ }^{1-3}$ Sources of ignition include electrocautery, lasers, oxidising sources such as oxygen, nitrous oxide and air, while fuels may include surgical drapes, preparing agents and materials.

\section{CASE REPORT}

A neonate on $1^{\text {st }}$ day of life presented to us with the complaint of not taking orally and bilious vomiting. This was a male child born through Cesarean section to a 30-year mother as a $3^{\text {rd }}$ child in family at the gestational age of 24 weeks. Child was weighing 850 grams. On examination, his abdomen was distended in the upper half of abdomen and few gut loops were also visible. Bowel sounds were audible on auscultation. His anal opening was normal and rectum was empty. His abdominal X-ray was obtained which showed few small bowel shadows, and a provisional diagnosis of jejunal atresia was made. He was optimised, and care for prematurity was provided. He maintained his saturation on oxygen support and needed two doses of surfactant over a period of one week. A central venous line was passed and total parenteral nutrition was started.

Correspondence to: Dr. Laraib Rasul, Department of Paediatric Surgery, Holy Family Hospital, Rawalpindi, Pakistan

E-mail: laraib.ru@gmail.com

Received: May 22, 2019; Revised: September 02, 2019;

Accepted: September 12, 2019

DOI: https://doi.org/10.29271/jcpsp.2020.07.760
His echocardiogram showed patent ductus arteriosus and ventricular septal defect. Hewas optimised for 4 more weeks, and all care regarding pre-maturity was provided. His weight increased to 1000 grams and decision for his surgery was made. As per our protocol, after intubation, child was covered with cotton in all areas including head, chest and all four limbs, except abdomen and back. After that, his abdomen was scrubbed with chlorhexidine and then allowed to dry. After placing sterile drapes, we applied preoperative opsite and skin incision was made with knife. After that, fascia was cut with monopolar cautery. Immediately, as we started electrocautery, a fire started under the drapes, which immediately caught the cotton wrapped around the child. The anesthesiologist stopped oxygen supply immediately and all drapes were removed. The fire involved the cotton, so sheet was wrapped around the child to control the fire. Fire was controlled early, and luckily, his airway remained maintained during all this process. Then, all cotton was removed and the burn area was assessed, which was calculated initially as $20 \%$ of total body surface area (TBSA). The incident was discussed with parents, and with a mutual consensus, surgery was done. He was having jejunal atresia, with blind ending proximal loop, $20 \mathrm{~cm}$ from duodenojejunal junction. In order to do a minimal surgery, both loops were exteriorised and abdomen was closed. Child was extubated safely and shifted back to nursery intensive care unit (NICU). His fluid requirement was changed and all the required care for burn was started including local wound care. After 24 hours, his TBSA was assessed again, as in case of fire injuries, initial assessment is usually not accurate. His 24 hours assessment showed it to be $40 \%$ TBSA, so again fluid requirementwas changed (Figure 1). Child ultimately developed sepsis inspite of septic care and succumbed to death after 4 days of this incident. Audit of this case revealed that during application of antiseptic solution before surgery, chlorhexidine was absorbed in the cotton and instead of giving it a time for drying, surgical field fire was ignited. Therefore, we changed our protocol and now we do not wrap child in cotton any more. 


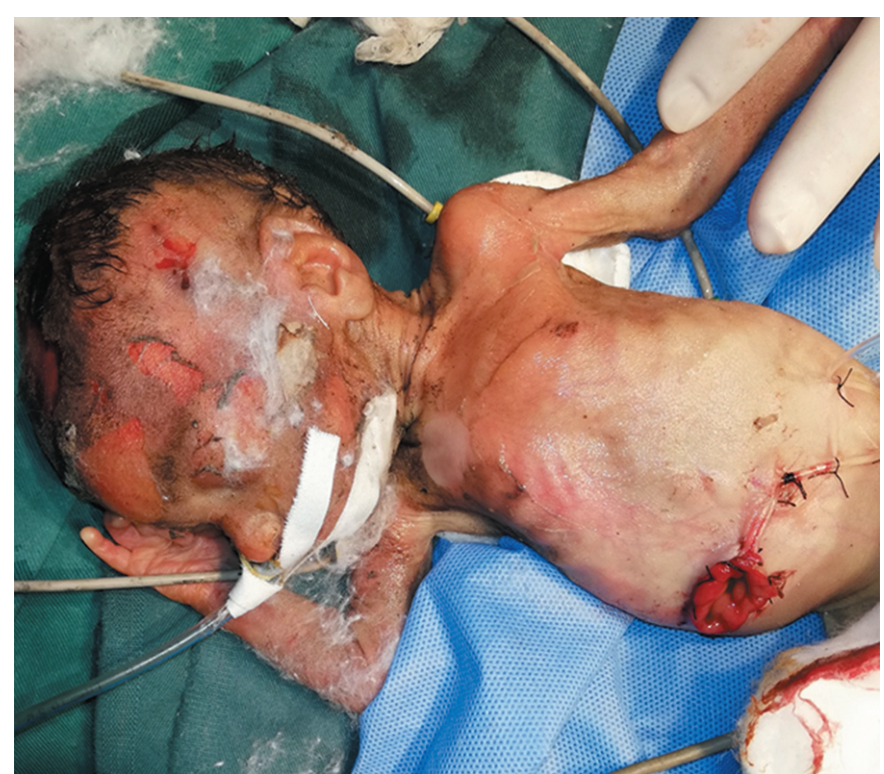

Figure 1: Full thickness burn over chest and scalp, and stoma at wound site.

\section{DISCUSSION}

Surgical field fire is a life-threatening hazard and is devastating for a patient. Fire is recognised as a complication of surgery for the last many years. Surgical field fire is not listed among intraoperative complications. There are three elements of fire: fuel (alcohol based solutions, drapes, PVC endotracheal tube, sponges, tinctures), source of oxygen, and heat. ${ }^{4}$ Almost $70 \%$ of fires are because of use of electrosurgical equipment. In $72 \%$ of cases, oxygen-rich environment contributed to fire. ${ }^{5}$ Use of antiseptic solutions provides fuel for surgical field fires. If patient is draped before drying of antiseptic solution, alcohol vapors become entrapped and contribute towards surgical field fires. There are two modes of electrocautery: cutting mode and coagulation mode. When cutting mode is used, it completes the triad for production of fire. ${ }^{6,7}$ There are many recommendations for prevention of surgical field fire: use of saline to inflate endotracheal tube cuff, use of lowest safe $\mathrm{FIO}_{2}$, use of suction device to clear products of diathermy produced in wound, no use of nitrous oxide, control all bleeding and maintaining dry operative field. Use of bipolar electrocautery minimises the risk of current leakage. Use wet sponges, and shave of skin for prevention of pooling of aseptic solution. Alcohol based solution should be completely wiped off before using diathermy. If using alcohol-based preparation, wait for at least 3 minutes for solution to evaporate. $^{8-10}$

Surgical field fire is a medical error and it can be prevented by using proper precautions. A recentstudy has shown its medicolegal implications and a median award payout to these patients. In addition, authors have reported two deaths among 33 cases suffering from surgical site fire. ${ }^{7}$ There are many causes of fire reported in literature. Although many protocols and precautions have been designed and are being practised, still these events happen everywhere. We, in resource-limited countries, thus have devised local protocols to preventfrom hypothermia. In our daily practice, we use to wrap neonates in cotton as it was done in this patient. After wrapping, during chlorohexidine paint, some solution got absorbed in cotton and it caught fire immediately as soon as three components were completed. So, we changed our protocols after this incident.

We conclude that all these events are devastating for family as well as doctors; and whole of the operation theatre staff, but they are preventable. It is important to preempt such events and preventive measuresneed to be taken.

\section{PATIENT'S CONSENT:}

Informed consent was obtained from patient's parents for publishing the data of the case.

\section{CONFLICT OF INTEREST}

Authors declared noconflict of interest.

\section{AUTHORS' CONTRIBUTION:}

LR, NL: Data acquisition and analysis, interpretation, drafting and final approval.

$\mathrm{RI}, \mathrm{NJ}$ : Conception and design, interpretation, critical revision and final approval.

$\mathrm{SH}$ : Design, critical revision and final approval.

\section{REFERENCES}

1. Singla AK, Campagna JA, Wright CD, Sandberg WS. Surgical field fire during a repair of bronchoesophageal fistula. Anesth Analg 2005; 100(4):1062-4.

2. Szentgyorgyi L, Leny A, Tamas E, Peterffy A. Intraoperative fires caused by alcoholic skin antiseptic and diathermy. Magy Seb 2008; 61 Suppl:71-3.

3. Tao JP, Hirabayashi KE, Kim BT, Zhu FA, Joseph JM, Nunery W. The efficacy of a midfacial seal drape in reducing oculofacial surgical field fire risk. Ophthalmic Plast Reconstr Surg 2013; 29(2):109-12.

4. MacDonald AG. A short history of fires and explosions caused by anaesthetic agents. BrJ Anaesth 1994; 72(6): 710-22.

5. Improper use of alcohol-based skin preps can cause surgical fires. Health Devices 2003; 32(11):441-3.

6. Khatiwada S, Bhattarai B, Acharya R, Chettri ST, Dhital D, Rahman TR. Surgical site fire: A case of evil spirit or lapsed communication. Nepal Med Coll J 2011; 13(2):140-1.

7. Choudhry AJ, Haddad NN, Khasawneh MA, Cullinane DC, Zielinski MD. Surgical fires and operative burns: Lessons learned from a 33-year review of medical litigation. Am J Surg 2017; 213(3):558-64.

8. Hoshijima H, Takeuchi R, Sato E, Kikuchi H. Accidental skin burns by fire of an antiseptic agent ignition by the spark of electric cautery. Masui 2010; 59(11):1438-40.

9. Mehta SP, Bhananker SM, Posner KL, Domino KB. Operating room fires: A closed-claims analysis. Anesthesiology 2013; 118(5):1133-9.

10. Seifert PC, Peterson E, Graham K. Crisis management of fire in the OR. Aorn J 2015; 101(2):250-63. 